\title{
Anti-inflammatory and anti-infectious effects of Evodia rutaecarpa (Wuzhuyu) and its major bioactive components
}

\author{
Jyh-Fei Liao' ${ }^{1}$ Wen-Fei Chiou², Yuh-Chiang Shen², Guei-Jane Wang ${ }^{2}$, Chieh-Fu Chen ${ }^{1,2^{*}}$
}

\begin{abstract}
This article reviews the anti-inflammatory relative and anti-infectious effects of Evodia rutaecarpa and its major bioactive components and the involvement of the nitric oxide synthases, cyclooxygenase, NADPH oxidase, nuclear factor kappa B, hypoxia-inducible factor 1 alpha, reactive oxygen species, prostaglandins, tumor necrosis factor, LIGHT, amyloid protein and orexigenic neuropeptides. Their potential applications for the treatment of endotoxaemia, obesity, diabetes, Alzheimer's disease and their uses as cardiovascular and gastrointestinal protective agents, analgesics, anti-oxidant, anti-atherosclerosis agents, dermatological agents and anti-infectious agents are highlighted. Stimulation of calcitonin gene-related peptide release may partially explain the analgesic, cardiovascular and gastrointestinal protective, anti-obese activities of Evodia rutaecarpa and its major bioactive components.
\end{abstract}

\section{Introduction}

Inflammation is a protective physiological response of an organism to chemical, physical, infectious agents, environmental toxins, ischemia or an antigen-antibody interaction. However, prolonged or overactive inflammation may cause tissue damage. Inflammation is very common manifested as body temperature change, edema, itch and pain, occasionally as serious as septic shock, tissue cirrhosis, necrosis or cancer. In the United States, over 500,000 patients suffer from sepsis triggered by severe systemic inflammation per year [1].

Various factors are involved in inflammation, such as calcium homeostasis, histamine, bradykinin, serotonin (5-HT), eicosanoids (prostaglandins, PG; thromboxanes, TX; leukotrienes, LT), platelet-activating factor, hormones (corticosterones), cytokines, interleukins (IL), chemotaxics, cyclooxygenase (COX), adhesion molecules, reactive oxygen species (ROS) $\left(\mathrm{H}_{2} \mathrm{O}_{2}, \mathrm{O}_{2}{ }^{-}\right)$, nitric oxide (NO) and substance P. Cells taking part in inflammation are erythrocytes, neutrophils, basophils, eosinophils, platelet, natural killer cells, lymphocytes, mast cells, antigen presenting cells and dendritic cells [2].

\footnotetext{
* Correspondence: chiehfuchen@gmail.com

${ }^{1}$ Institute of Pharmacology, National Yang-Ming University, No 155, Sec 2,

Linong Road, Taipei 112, Taiwan

Full list of author information is available at the end of the article
}

Diseases and syndromes, such as arthritis, atherosclerosis, atopic dermatitis, brain or heart stroke, cancer, cataract, diabetes, neurodegeneration, pain, rhinitis and septic shock, are all related to inflammation.

Natural products may still be the most abundant sources for new drug development. Aspirin and corticosterone are two well known examples for anti-inflammatory products derived from Nature. Favonoids are potential therapeutic agents for the treatment of inflammation, heart disease and cancer [3]. This article reviews the anti-inflammatory relative and anti-infectious effects of Evodia rutaecarpa (Wuzhuyu) and its major bioactive components such as dehydroevodiamine (DeHE), evodiamine (Evo) and rutaecarpine (Rut).

Mechanisms of anti-inflammatory relative effects of Evodia rutaecarpa and its bioactive components are summarized in Additional file 1.

\section{Effects on nitric oxide (NO) system and nitric oxide} synthase (NOS)

While NO is involved in the blood pressure regulation, smooth muscle relaxation, platelet aggregation, neurotransmission, long-term potentiation, penile erection, apoptosis and immune response, over-expression of inducible nitric oxide synthase (iNOS) plays an important role in systemic or local, acute or chronic 
inflammation such as septic shock and rheumatoid arthritis $[4,5]$.

A study on the cardiovascular effects of DeHE, Evo and Rut found that Rut produced a full NO-dependent vasodilatation whereas Evo and DeHE produced a partially endothelium-dependent effect at $50 \%$ and $10 \%$ respectively [6]. Apart from endothelium dependence, alpha 1-adrenoceptor blockade, $\mathrm{K}^{+}$channel activation and $\mathrm{Ca}^{2+}$ channel blockade were also involved in the vasorelaxant effect of DeHE [7]. Coupled with influx of extracellular calcium, Rut produced the endothelium-dependent vasorelaxant effect by activation of endothelium NOS and release of NO without pertussis toxin-sensitive Gi protein and other $\mathrm{G}$ proteins or phospholipase $\mathrm{C}$ activation being involved [8]. Another study using the whole-cell patch-clamp method found that Rut inhibited the L-type voltagedependent calcium channels of rat vascular smooth muscle cells and increased NO release through opening of non-voltage-dependent calcium channels in the endothelial cells $[9,10]$.

In other smooth muscles, Evo was shown to possess a potent corporal relaxing effect attributed to endothelium-independent properties and was tested as a potential agent for the treatment of erectile dysfunction in aged animals [11].

DeHE was found to inhibit NO production by interfering not only with the priming signal initiated by interferon-gamma but also with iNOS synthesis while Evo affected the former only [12]. Ethanol extract of Evodia rutaecarpa dose-dependently prevented the circulation failure, vascular hyporeactivity to phenylephrine, liver dysfunction and reduced the NO over-production in plasma in lipopolysaccharide (LPS)-induced endotoxaemic rats [13]. Evodia rutaecarpa ethanol extract exhibited potent antioxidative effects in neutrophils and that in microglial cells Evodia rutaecarpa ethanol extract, DeHE, Evo and Rut all inhibited the LPS-induced NO production and iNOS expression [14].

\section{Effects on nuclear factor kappa B (NF-kappa B), cyclooxygenase (COX), 5-lipoxygenase(5-LO), prostaglandins (PG), serotonin (5-HT), interleukins (IL), tumor necrosis factor-alpha (TNF- $\alpha$ ) and LIGHT}

COX and LO are enzynes involved in the metabolism arachidonic acid, thus formation of PG, IL, and other metabolites which related to inflammation [2].

A study found that Evo and Rut strongly inhibited $\mathrm{PGE}_{2}$ synthesis in LPS-treated RAW 264.7 cells and that Evo but not Rut inhibited COX-2 induction and NFkappa B activation. Goshuyuamide ||, another Evodia rutaecarpa active component, inhibited 5-LO, thereby reducing leukotriene (LT) synthesis; however, these three compounds did not inhibit iNOS mediated NO production from cells up to $50 \mu \mathrm{M}$ [15]. Another study reported that DeHE inhibited LPS-induced iNOS and COX-2 and their mRNAs expression in RAW 264.7 cells, probably through the suppression of NF-kappa B activation in the transcriptional level [16]. Evo was found to inhibit hypoxia-induced inflammatory response by repressing not only COX-2, COX-2 mRNA and iNOS expression but also $\mathrm{PGE}_{2}$ release in a concentration-dependent manner in RAW264.7 cells under hypoxia condition, mediated via dephosphorylation of the serine/threonine kinases Akt and p70S6 kinase regulating the translation process of hypoxia-inducible factor-1 alpha by Evo [17]. A study demonstrated that Rut is a new class of COX-2 inhibitor partially contributing its in vivo anti-inflammatory activities on lamda-carrageenan induced paw edema in rats [18].

Wuzhuyu Tang (WT), a Chinese medicine formula for migraine treatment, is composed of Evodia fruit, Ginger, Ginseng, and Jujube. A study on WT reported regulatory effects of various components in WT on tryptophan hydroxylase 2 (TPH2, the rate limiting enzyme for 5 -HT biosynthesis in brain) promoter, suggesting that the effects of WT on migraine could be due to its stimulating effects on TPH2 promoter and promotion of the 5-HT synthesis and release in the brain [19].

In human mononuclear cells, $10 \%$ to $30 \%$ of Evodia rutaecarpa extracts were found to stimulate the secretion of IL- 1 beta, IL- 6 , TNF- $\alpha$ and granulocyte-macrophage colony-stimulating factor; however, more than $40 \%$ of Evodia rutaecarpa extract lost its stimulating effect. Evodia rutaecarpa extract showed better stimulating effect when reacted with mononuclear cell for 18 or 24 hours than one or three hours [20,21].

Homologous to Lymphotoxin, exhibits inducible expression, competes with Herpes Simplex Virus Glycoprotein $\mathrm{D}$ for binding to Herpes Virus entry Mediator (HVEM), a receptor on T lymphocytes (LIGHT) showed inducible expression and acted as a new player in the atherogenesis [22]. Evo and Rut decreased LIGHTinduced production of ROS, IL-8, monocyte chemoattractant protein-1, TNF- $\alpha$, IL- 6 , and the expression of chemokine receptor (CCR) 1, CCR2 and intracellular adhesion molecule 1 and the phosphorylation of extracellular-signal-regulated kinases (ERK) $1 / 2$ and p38 mitogen-activated protein kinase (MAPK) via decreasing ROS production and NADPH oxidase activation. Evo and Rut were considered as potential anti-atherosclerosis agents [23].

\section{Capsaicin-like effects}

Used as an analgesic, capsaicin, the major bioactive component of Capsicum frutescens L., is a vanilloid receptor agonist [24]. Capsaicin-sensitive sensory neurons are nociceptive neurons that release calcitonin gene-related peptide (CGRP) on activation. Capsaicin-sensitive sensory 
neurons are rich in transient receptor potential channel vanilloid type 1 (TRPV1) which plays a fundamental role in pain and involves in the protective effects on cardiovascular and gastrointestinal systems. A study found that TRPV1 could be activated by endogenous cannabinoids (anandamide, $\mathrm{N}$-archidonoyl dopamine, $\mathrm{N}$-oleoyldopamine) or by exogenous agonists such as capsaicin, Evo and Rut which in turn stimulated the CGRP relaease [25].

An earlier study found that oral administration of ethanol extract of Evodia rutaecarpa to mice reduced the acetic acid induced abdominal stretch [26]. Another study confirmed that Evo and Rut were partially responsible for the analgesic effects [27]. Limonin from Evodia rutaecarpa was also found to be analgesic [28].

Evo possesses vanilloid receptor agonistic activities comparable to capsaicin in guinea-pig isolated bronchus [29] and atria [30], and suppresses acetic acid-induced writhing by desensitizing visceral sensory nerves [31]. A study found that Evo was an agonist for the vanilloid receptor TRPV1 in rat, about 3-19 fold less potent than capsaicin [32]. Moreover, Evo was found to protect bovine serum albumin induced guinea-pig cardiac anaphylaxis by stimulation of CGRP release [33] and exert protection against myocardial ischemia-reperfusion injury in rats by activation of vanilloid receptors to stimulate the CGRP release [34].

Rut did not demonstrate bronchoconstrictive effects in guinea-pig isolated bronchus [29]. Rut increased the CGRP and decreased TNF- $\alpha$ with significant improvement of cardiac function and inhibition of the sinus tachycardia in antigen induced cardiac anaphylactic injury of guinea-pig hearts [35]. Rut was also found to release CGRP to inhibit vasoconstriction induced by anaphylaxis in guinea-pigs [36]. Similarly, the cardioprotective effect of Rut on myocardial ischemiareperfusion injury was caused by vanilloid receptor activation to evoke CGRP release in normal [37] or spontaneously hypertensive rats (SHR) [38]. Rut inhibited hypoxia/reoxygenation induced apoptosis in primary rat hippocampal neurons via TRPV1- $\left(\mathrm{Ca}^{2+}\right)_{\mathrm{i}}$-dependent and phosphoinositide 3-kinase (PI3K)/Akt signaling pathway [39]. Furthermore, the protective effects of Rut on acetylsalicylic acid and stress-induced gastric mucosa injury were related to stimulation of endogenous CGRP release via activation of vanilloid receptor [40]. Rut also protected the gastric mucosa against injury induced by ethanol via stimulating the release of CGRP to attenuate ethanol-induced elevation of asymmetric dimethylarginine levels [41].

A review article reported that CGRP played an important role in the initiation, progression and maintenance of hypertension and that in contrast the increase in CGRP levels or the enhancement of vascular sensitivity response to CGRP served as a beneficial compensatory depressor role in the development of hypertension [42]. Furthermore, there are therapeutic possibilities of CGRP in hypertension [43]. Effects of Rut on cardiovascular system were reported to act through the release of CGRP, including the depressor and vasodilator [44], the hypotensive effects in the phenol-induced hypertensive rats [45], the hypotensive effects and reduction of mesenteric artery hypertrophy in removascular hypertensive rats [46] and the hypotensive and anti-platelet effects (inhibits the relaease of platelet-derived tissue factor) in SHR [47]. Effects of Rut to lower systolic blood pressure and reverse mesenteric artery remodeling were found to be related to increased expression of prolylcarboxypeptidase in the circulation and small arteries in renovascular hypertensive rats [48]. However, Rut inhibited platelet aggregation in human platelet-rich plasma by inhibiting $\mathrm{TXA}_{2}$ formation, phosphoinositide breakdown and phospholipase $\mathrm{C}$ [49-51]. CGRP could work as an endogenous protective substance to counteract endothelial progenitor cells senescence in hypertension and the accelerated endothelial progenitor cells senescence in hypertension is related to the reduction of CGRP while Rut could reverse endothelial progenitor cell senescence along with an elevation in CGRP production in SHR and reverse angiotensin II-induced CGRP mRNA expression in endothelial progenitor cells [52].

Rut solid dispersion significantly increased the blood concentration, accompanied by significant hypotensive effects in SHR in a dose-dependent manner [53]. The 14- $\mathrm{N}$ atom of Rut might be the key site for the activity and simple substitute in indole-ring or quinazoline-ring would not enhance the vasodilator effects unless in a proper position and with a proper group [54].

\section{Effects on Alzheimer's disease}

Alzheimer's disease, impairment of memory and cognitive ability caused by the loss of hippocampal and cortical neurons, is related to accumulations of beta-amyloid [55] and disproportionate deficiency of acetylcholine [56]. Treatment for Alzheimer's disease includes transmitter replacement therapies, anti-oxidants, neuronal calcium channel blockers, anti-apoptotic agents, antiinflammatory agents, estrogens, nerve growth factors and drugs that inhibit secretase activity and prevent or block beta-amyloid formation in the brain $[57,58]$.

DeHE $\mathrm{HCl}$ was found to increase the cerebral blood flow in anesthetized cats [59]. In a screening of 29 natural products, Evodia rutaecarpa demonstrated a strong inhibitory effect on acetylcholinesterase in vitro and an anti-amnesic effect in vivo. The active component of Evodia rutaecarpa was identified as DeHE $\mathrm{HCl}$ [60]. A study suggested that DeHE $\mathrm{HCl}$ might be an effective drug not only for the Alzheimer's disease type but also 
for the vascular type of dementia [61]. Our study reported that DeHE pretreatment attenuated intracerebroventricular administration of beta-amyloid peptide (2535 ) and intraperitoneal administration of scopolamine induced amnesia in mice [62]. Furthermore, pre-administration of DeHE via vena caudalis for one week effectively improved the Wortmannin and GF-109 203X (WT/GFX) induced spatial memory retention impairment of rats, antagonized tau hyperphosphorylation at multiple Alzheimer's disease site and arrested the overactivation of glycogen synthase kinase- 3 induced by WT/ GFX [63]. DeHE did not cause any serious adverse effects at the dose levels in the experimental animals [64]. Some novel inhibitors of acetyl- and butyrylcholinesterase derived from DeHE and Rut were also reported [65].

DeHE $\mathrm{HCl}$ could provide long-lasting facilitation of synaptic transmission that depended on the activation of both the muscarinic and N-methyl-D-aspartate receptors in the Cornu Ammonis area 1 region of rat hippocampal slices on the electrical stimulation evoked field excitatory postsynaptic potentials [66]; however, chronic exposure to DeHE concentration-dependently inhibited glutamate uptake and release in the cultured cerebellar cells [67]. In rat brain slices, DeHE attenuated calyculin $\mathrm{A}$, a protein phosphatase (PP)-2A and PP-1inhibitor, and induced Alzheimer's disease-like tau hyperphosphorylation [68]. Evodia officinalis extract demonstrated the most protective effects among 10 kinds of plant extracts against the carboxy-terminal 105 amino acid fragments of amyloid precursor protein induced neurotoxicity [69].

\section{Themoregulative effects, anti-obese, anti-adipogenic and anti-diabetic effects}

Among the Evodia fruit alkaloids(hydroxy-Evo, Evo, Rut and evocarpine), Evo prevented the chlorpromazine induced decrease of body temperature in rats [70]; however, intraperitoneal injection of DeHE or Evo caused a dose-related hypothermia in afebrile rats at $20^{\circ} \mathrm{C}$. Moreover, both DeHE and Evo attenuated the febrile response induced by intrahypothalamic injection of exogenous pyrogen in rats [71].

Evo was found to mimic the capsaicin-like anti-obese activities [72]; however, in uncoupling protein-1 (UCP1)knockout mice, Evo triggered a UCP1-independent mechanism to prevent diet-induced obesity [73]. Furthermore, the anti-adipogenic effects of Evo were not blocked by the specific TRPV1 antagonist capsazepine in 3T3-L1 preadipocytes whereas Evo stimulated the phosphorylation of epidermal growth factor receptor (EGFR), protein kinase $C$ alpha and ERK, all of which were reduced by EGFR inhibitor [74]. Evo inhibited human white preadipocyte differentiation accompanied by up-regulation of both GATA binding protein 2 and 3 mRNA and protein expression [75]. Evo also inhibited the adipocyte differentiation of 3T3-21 and C3H1OT1/2 cells and inhibited the obesity in $d b / d b$ mice. Evo improved the undesirable effects of rosiglitazone, including adipogenesis, body weight gain and hepatotoxicity, while preserving its blood-glucose-lowering effects [76].

Orexin [77] and melanin-concentrating hormone $(\mathrm{MCH})$ [78] regulate food intake, arousal and motivated behavior in lateral hypothalamic area. In fed and in hyperinsulinemic obese mice, insulin signaling led to nuclear exclusion of forkhead transcription factor Foxa2 and reduces expression of $\mathrm{MCH}$ and orexin [79]. As constitutive and conditional activation of Foxa2 in the brain increased neuronal $\mathrm{MCH}$ and orexin expression, it was suggested that pharmacological inhibition of Foxa2 phosphorylation might improve levels of physical activity, overall health and longevity [80].

Administration of Evo to juvenile rats decreased rate of food intake and body weight increase, reduced orexigenic neuropeptide Y (NPY) and agouti-gene related protein mRNA levels and NPY peptide level but increased the circulating level of leptin [81]. In high-fat-diet-induced $(\mathrm{C} 57 \mathrm{BL} / 6)$ and leptin-deficient $(o b / o b)$ obese mice, Rut ameliorated obesity by inhibiting food intake [82].

Aldose reductase inhibitors are potential drugs for treating diabetic complications [83]. Rhetsinine from Evodia rutaecarpa inhibited aldose reductase activity and was considered potentially useful in the treatment of diabetic complications [84].

\section{Gl effects}

One of the most important clinic application of Evodia Fructus is treatment of discomfort or chill of stomach.

Water extract of Evodia rutaecarpa inhibited the intestinal transit (anti-transit effect) and castor oilinduced diarrhea in mice [85]; however, the water extract of Evodia rutaecarpa protected the ethanolinduced rat gastric lesions $[86,87]$. As mentioned earlier, the protective effects of Rut on acetylsalicylic acid, stress and ethanol-induced gastric mucosa injury were related to stimulation of endogenous CGRP release via activation of vanilloid receptor $[40,41]$.

Evo inhibited both gastric emptying and gastrointestinal transit in male rats via a mechanism involving cholecystokinin $(\mathrm{CCK})$ release and $\mathrm{CCK}_{1}$ receptor activation [88]. DeHE $\mathrm{HCl}$ also exhibited anti-transit effect [64].

Anti-emetic effects of the ethanol extracts of WT were demonstrated via 5-HT and histamine receptors [89].

\section{Dermatological applications}

Among 100 herbal extracts screened for anti-oxidant activity and free radical scavenging activity, Evodia officinalis was one of the 14 potential sources of antioxidants [90]. 
Evodia rutaecarpa, Evo and Rut inhibited immunoglobulin E (IgE)-antigen complex-induced passive cutaneous anaphylaxis reaction and compound 48/80-induced scratching behaviors in mice. Evo and Rut inhibited IgEantigen complex-induced TNF- $\alpha$ and IL-4 protein expression in RB2-2H3 cells, suggesting that Evo and Rut could be used for the treatment of atopic dermatitis and rhinitis [91].

Extract of Evodia officinalis showed a potent inhibitory effect on ultraviolet B (UVB) induced matrix metalloproteinase (MMP)-1 production in human skin fibroblasts [92]. A defined mixture composed of Rut, DeHE and evodin was shown to inhibit UVB-induced $\mathrm{PGE}_{2}$ released by keratinocytes in vitro and methyl nicotinate-induced erythema in human skin [93]. Rut also inhibited ultraviolet A (UVA) induced ROS generation and suppressed UVA or $\mathrm{H}_{2} \mathrm{O}_{2}$-induced increase in the expression of MMP-2 and MMP-9 in HaCaT human keratinocytes [94].

\section{Anti-anoxic effects}

Extract of Evodia rutaecarpa exerted an antianoxic effect in the KCN-induced anoxia model in mice [95]. Cholinergic mechanism was found to be involved in the antianoxic action of Evo which is an active component of Evodia rutaecarpa [96].

\section{Anti-infectious effects}

Anti-infectious, or chemotherapeutic, agents for the treatment of protozoal, helminth, and microbial diseases are not anti-inflammatory agents and different from the pharmacodynamic agents which affected the physiological, biochemical, or immunological function of host. The need to develop new chemotherapeutic agent for the widespred antibiotic-resistant pathogens are very important but less success.

Among 300 herbal extracts screened for the anti-hepatitis B surface antigen capability, Evodia rutaecarpa was one of the ten effective herbs [97]. Atanine (3-dimethylallyl-4-methoxy-2-quinolone) was found as an active anthelmintic compound in Evodia rutaecarpa [98]. Six quinolone alkaloids (ie evocarpine, 1-methyl2-[(4Z,7Z)-4,7-tridecadienyl]-4(1H)-quinolone, 1-methyl2-[(6Z,9Z)-6.9-pentadecadienyl]-4(1H)-quinolone, 1-methyl-2-undecyl-4(1H)-quinolone, dihydroevocarpine and 1-methyl-2-pentadecyl-4(1H)-quinolone) isolated from Evodia rutaecarpa showed potent anti-Helicobacter pylori activity [99]. Two alkyl quinolone compounds, namely 1-methyl-2-[(Z)-8-tridecenyl $]-4-(1 \mathrm{H})$-quinolone and 1-methyl-2-[(Z)-7-tridecenyl $]-4-(1 \mathrm{H})$-quinolone, from Evodia rutaecarpa were anti-bacterial agents highly selective in vitro against $H$. pylori and almost non-active against other intestinal pathogens [100]. In vivo studies on $H$. pylori infected Mongolian gerbils demonstrated that alkyl methyl quinolone compounds from Evodia rutaecarpa decreased the number of $H$. pylori and inhibited the $H$. pylori respiration [101,102].

Three synthesized 2-alkenyl-4(1H)-quinolone compounds, one of which is found in Evodia rutaecarpa demonstrated vasodilating and antibacterial effects [103]. Evodia rutaecarpa extract was reported to possess bactericidal activity against gram-positive cocci, $P$ aeruginose and $C$ albicans [104]. Similarly, extracts of Evodia elleryana leaves, stem wood, stem bark, root wood, root bark and petrol, dichloromethane, ethyl acetate partition fractions showed a broad spectrum of anti-bacterial activity [105]. Extract of Evodia elleryana bark also inhibited Mycobacterium tuberculosis [106]. Ethyl acetate extract of Evodia fatraina stem bark showed moderate in vitro anti-malarial activity against Plasmodium falciparum while the ethanol extract exhibited 65\% suppression of Plasmodium berghei in mice [107].

\section{Conclusion}

Stimulation of CGRP release may partially explain the analgesic, cardiovascular and gastrointestinal protective, anti-obese activities of Evodia rutaecarpa and its major bioactive components. Other direct actions by the active components of Evodia rutaecarpa on different targets may account for various pharmacological effects of Evodia rutaecarpa.

\section{Additional material}

\begin{abstract}
Additional file 1: Mechanisms of anti-inflammatory relative effects of Evodia rutaecarpa and its bioactive components with potential clinic applications. The known mechanisms for anti-inflammatory effects of Evodia rutaecarpa extracts and its bioactive components such as dehydroevodiamine (DeHE), evodiamine (Evo) and rutaecarpine (Rut) are summarized and their potential clinic applications are suggested in this file. Some reported pharmacological effects of Wuzhuyu Tang (composed of Evodia fruit, Ginger, Ginseng, and Jujube) are also listed. Please refer to the text for the detail and references.
\end{abstract}

\section{Abbreviations}

5-HT: 5-hydroxytryptamine, serotonin; 5-LO: 5-lipoxygenase; CCK: cholecystokinin; CCR: chemokine receptor; CGRP: calcitonin gene-related peptide; COX: cycloxygenase; DeHE: dehydroevodiamine; EGFR: epidermal growth factor receptor; ERK: extracellular-signal-regulated kinases; Evo: evodiamine; HSV: herpes simplex virus; IgE: immunoglobulin E; IL: interleukin; iNOS: inducible nitric oxide synthase; LIGHT: Homologous to Lymphotoxin, exhibits inducible expression, competes with Herpes Simplex Virus Glycoprotein D for binding to Herpes Virus entry Mediator (HVEM), a receptor on T lymphocytes; LPS: lipopolysaccharide; LT: leukotriene; $M C H$ : melanin-concentrating hormone; MMP: matrix metalloproteinase; NF-kappa B: nuclear factor kappa B; NO: nitric oxide; NOS: nitric oxide synthase; NPY: neuropeptide Y; PG: prostaglandins; PP: protein phosphatase; ROS: reactive oxgen species; Rut: rutaecarpine; SHR: spontaneously hypertensive rats; TNFa: tumor necrosis factor-alpha; TPH2: tryptophan hydroxylase 2; TRPV1: transient receptor potential channel vanilloid type 1; TX: thromboxanes; UCP1: uncoupling protein-1; UVA: ultraviolet A radiation; UVB: ultraviolet B radiation; WT: Wuzhuyu Tang; WT/GFX: Wortmannin and GF-109203X 


\section{Author details}

${ }^{1}$ Institute of Pharmacology, National Yang-Ming University, No 155, Sec 2 Linong Road, Taipei 112, Taiwan. ${ }^{2}$ National Research Institute of Chinese Medicine, No 155-1, Sec 2, Linong Road, Taipei 112, Taiwan.

\section{Authors' contributions}

CFC proposed the review and wrote the manuscript. JFL searched the literature, compiled and reviewed the information and revised the manuscript. WFC reviewed the information on NO, NOS and endotoxaemic rats. YCS reviewed the information on neutrophils and microglial cells. GJW reviewed the information on vascular smooth muscle cell, endothelial cell and electropharmacology. All authors read and approved the final version of the manuscript.

\section{Competing interests}

The authors declare that they have no competing interests.

Received: 9 September 2010 Accepted: 14 February 2011 Published: 14 February 2011

\section{References}

1. Angus DC: Epidemiology of severe sepsis in the United States: Analysis of incidence, outcome, and associated costs of care. Crit Care Med 2001 29:1303-1310.

2. Smyth EM, Burke A, Fitzgerald GA: Lipid-derived autacoids: Eicosanoids and platelet-activating factor. In Goodman and Gilman's the Pharmacological Basis of Therapeutics.. 11 edition. Edited by: Brunton LL, Lazo JS, Parker KL. New York: McGraw-Hill Med Pub Divi 2006:653-670.

3. Elliott MJ, Chitham K, Theoharis LT: The effects of plant flavonoids on mammalian cells. Implications for inflammation, heart disease, and cancer. Pharmacol Rev 2000, 52:673-751.

4. Moncada S, Palmer RMJ, Higgs EA: Nitric oxide: physiology, pathophysiology, and pharmacology. Pharmacol Rev 1991, 43:109-142.

5. Stefanovic Racic M, Stadler J, Evans CH: Nitric oxide and arthritis. Arthritis Rheum 1993, 36(8):1036-1044.

6. Chiou WF, Liao JF, Chen CF: Comparative study of the vasodilatory effects of three quinazoline alkaloids isolated from Evodia rutaecarpa. $J$ Nat Prod 1996, 59(4):374-378.

7. Chiou WF, Liao JF, Shum AY, Chen CF: Mechanisms of vasorelaxant effect of dehydroevodiamine: A bioactive isoquinazolinocarboline alkaloid of plant origin. J Cardiovasc Pharmacol 1996, 27(6):845-853.

8. Chiou WF, Shum AY, Liao JF, Chen CF: Studies of the cellular mechanisms underlying the vasorelaxant effects of rutaecarpine, a bioactive component extracted from a herbal drug. J Cardiovasc Pharmacol 1997, 29(4):490-498.

9. Wang GJ, Shan J, Pang PKT, Yang MCM, Chou CJ, Chen CF: The vasorelaxing action of rutaecarpine: Direct paradoxical effects of intracellular calcium concentration of vascular smooth muscle and endothelial cells. J Pharmacol Exp Ther 1996, 276:1016-1021.

10. Wang GJ, Wu XC, Chen CF, Lin LC, Huang YT, Shan J, Pang PKT: Vasorelaxing action of rutaecarpine: Effects of rutaecarpine on calcium channel activities in vascular endothelial and smooth muscle cells. $J$ Pharmacol Exp Ther 1999, 289:1237-1244.

11. Chiou WF, Chen CF: Pharmacological profile of evodiamine in isolated rabbit corpus cavernosum. Eur J Pharmacol 2002, 446:151-159.

12. Chiou WF, Sung YJ, Liao JF, Shum AY, Chen CF: Inhibitory effect of dehydroevodiamine and evodiamine on nitric oxide production in cultured murine macrophages. J Nat Prod 1997, 60(7):708-711.

13. Chiou WF, Ko HC, Chen CF, Chou CJ: Evodia rutaecarpa, protects against circulation failure and organ dysfunction in endotoxaemic rats through modulating nitric oxide release. J Pharm Pharmacol 2002, 54:1399-1405.

14. Ko HC, Wang YH, Liou KT, Chen CM, Chen CH, Wang WY, Chang S, Hou YC, Chen KT, Chen CF, Shen YC: Anti-inflammatory effects and mechanisms of the ethanol extract of Evodia rutaecarpa and its bioactive components on neutrophils and microglial cells. Eur J Pharmacol 2007, 555(2-3):211-217.

15. Choi YH, Shin EM, Kim YS, Cai XF, Lee JJ, Kim HP: Anti-inflammatory principles from the fruits of Evodia rutaecarpa and their cellular action mechanisms. Arch Pharm Res 2006, 29(4):293-297.

16. Noh EJ, Ahn KS, Shin EM, Jung SH, Kim YS: Inhibition of lipopolysaccharide-induced iNOS and COX-2 expression by dehydroevodiamine through suppression of NF-Kappa B activation in RAW 264.7 macrophages. Life Sci 2006, 79:695-701.

17. Liu YN, Pan SL, Liao CH, Huang DY, Guh JH, Peng CY, Chang YL, Teng CM: Evodiamine represses hypoxia-induced inflammatory proteins expression and hypoxia-inducible factor 1 alpha accumulation in RAW 264.7. Shock 2009, 32(3):263-269.

18. Moon TC, Murakami M, Kudo I, Son KH, Kim HP, Kang SS, Chang HW: A new class of COX-2 inhibitor, rutaecarpine from Evodia rutaecarpa. Inflamm Res 1999, 48(12):621-625.

19. Wang $Y$, Lei F, Wang $S$, Hu J, Zhan H, Xing D, Du L: Regulatory effects of Wuzhuyutang (Evodia prescription) and its consisting herbs on TPH2 promoter. Zhongguo Zhong Yao Za Zhi 2009, 34(17):2261-2264.

20. Chang CP, Chang JY, Wang FY, Tseng J, Chang JG: The effect of Evodia rutaecarpa extract on cytokine secretion by human mononuclear cells in vitro. Am J Chin Med 1995, 23(2):173-180.

21. Chang JY, Yang TY, Chang CP, Chang JG: The effect of 'chi-han (hot nature)' Chinese herbs on the secretion of IL-1 beta and TNF-alpha by mononuclear cells. Kaohsiung J Med Sci 1996, 12(1):18-24.

22. Bobik A, Kalinina N: Tumor necrosis factor receptor and ligand superfamily family members TNFRSF 14 and LIGHT: New players in human atherogenesis. Arterioscler Thromb Vasc Biol 2001, 21:1873-1875.

23. Heo SK, Yun HJ, Yi HS, Noh EK, Park SD: Evodiamine and rutaecarpine inhibit migration by LIGHT via suppression of NADPH oxidase activation. J Cell Biochem 2009, 107(1):123-133.

24. Caterina M, Julius D: The vanilloid receptor: a molecular gateway to the pain pathway. Annu Rev Neurosci 2001, 24:487-517

25. Peng L, Li YJ: The vanilloid receptor TRPV-1: Role in cardiovascular and gastrointestinal protection. Eur J Pharmacol 2010, 627(1-3):1-7.

26. Chow SY, Chen SM, Yang CM: Pharmacological studies on Chinese herbs (3): Analgesic effects of 27 Chinese drugs in mice. J Formosan Med Asso 1976, 75:349-357.

27. Matsuda H, Wu TX, Tanaka T, Linuma M, Kubo M: Antinociceptive activities of $70 \%$ methanol extract of Evodiae Fructus (fruit of Evodia rutaecarpa var. bodinieri ) and its alkaloidal components. Biol Pharm Bull 1997, 20(3):243-248

28. Matsuda H, Yoshikawa M, Linuma M, Kobo M: Antinociceptive and antiinflammatory activities of limonin isolated from the fruits of Evodia rutaecarpa var. bodinieri. Planta Med 1998, 64(4):339-342.

29. Kobayashi Y, Nakano Y, Hoshikuma KM, Yokoo Y, Kamiya T: The bronchoconstrictive action of evodiamine, an indoloquinazoline alkaloid isolated from the fruits of Evodia rutaecarpa, on guinea-pig isolated bronchus: Possible involvement on vanilloid receptors. Planta Med 2000 66(6):526-530.

30. Kobayashi Y, Hoshikuma K, Nakano Y, Yokoo Y, Kamiya T: The positive inotropic and chronotropic effects of evodiamine and rutaecarpine, indoloquinazoline alkaloids isolated from the fruits of Evodia rutaecarpa, on the guinea-pig isolated right atria: Possible involvement of vanilloid receptors. Planta Med 2001, 67(3):244-248.

31. Kobayashi Y: The nociceptive and anti-nociceptive effects of evodiamine from fruits of Evodia rutaecarpa in mice. Planta Med 2003, 69(5):425-428

32. Pearce LV, Petukhov PA, Szabo T, Kedei N, Bizik F, Kozikowski AP, Blumberg PM: Evodiamine functions as an agonist for the vanilloid receptor TRPVI. Org Biomol Chem 2004, 2(16):2281-2286.

33. Rang WQ, Du YH, Hu CP, Ye F, Tan GS, Deng HW, Li YJ: Protective effects of calcitonin gene-related peptide-mediated evodiamine on guinea-pig cardiac anaphylaxis. Naunyn Schmiedebergs Arch Pharmacol 2003, 367(3):306-311.

34. Rang WQ, Du YH, Hu CP, Ye F, Xu KP, Peng J, Deng HW, Li YJ: Protective effects of evodiamine on myocardial ischemia-reperfusion injury in rats Planta Med 2004, 70(12):1140-1143.

35. Yi HH, Rang WQ, Deng PY, Hu CP, Liu GZ, Tan GS, Xu KP, Li YJ: Protective effects of rutaecarpine in cardiac anaphylactic injury is mediated by CGRP. Plant Med 2004, 70(12):1135-1139.

36. Yu J, Tan GS, Deng PY, Xu KP, Hu CP, Li YJ: Involvement of CGRP in the inhibitory effect of rutaecarpine on vasoconstriction induced by anaphylaxis in guinea pig. Regul Pept 2005, 125(1-3):93-97.

37. Hu CP, Xiao L, Deng HW, Li YJ: The cardioprotection of rutaecarpine is mediated by endogenous calcitonin release-gene peptide through activation of vanilloid receptors in guinea-pig hearts. Planta Med 2002, 68(8):705-709. 
38. Li D, Zhang XL, Chen L, Yang Z, Deng HW, Peng L, Li YJ: Calcitonin generelated peptide mediates the cardioprotective effects of rutaecarpine against ischaemia-perfusion injury in spontaneously hypertensive rats. Clin Exp Pharmacol Physiol 2009, 36(7):662-667.

39. Dai Z, Xiao J, Lin SY, Cui L, Hu GY, Jiang DJ: Rutaecarpine inhibits hypoxia/ reoxygenation-induced apoptosis in rat hippocampal neurons. Neuropharmacology 2008, 55(8):1307-1312.

40. Wang L, Hu CP, Deng PY, Shen SS, Zhu HQ, Ding JS, Tan GS, Li YJ: The protective effects of rutaecarpine on gastric mucosa injury in rats. Planta Med 2005, 71(5):416-419.

41. Liu YZ, Zhou Y, Li D, Wang L, Hu GY, Peng J, Li YJ: Reduction of asymmetric dimethylarginine in the protective effects of rutaecarpine on gastric mucosal injury. Can J Physiol Pharmacol 2008, 86(10):675-681.

42. Deng PY, Li YJ: Calcitonin gene-related peptide and hypertension. Peptides 2005, 26(9):1675-1685.

43. Márquez-Rodas L, Longo F, Rothlin RP, Balfagón G: Phathophysiology and the therapeutic possibilities of calcitonin gene-related peptide in hypertension. J Physiol Biochem 2006, 62(1):45-46.

44. Hu CP, Xiao L, Deng HW, Li YJ: The depressor and vasodilator effects of rutaecarpine are mediated by calcitonin gene-related peptide. Planta Med 2003, 69(2):125-129.

45. Deng PY, Ye F, Cai WJ, Tan GS, Hu CP, Deng HW, Li YJ: Stimulation of calcitonin gene-related peptide synthesis and release: mechanisms for a novel antihypertensive drug, rutaecarpine. J Hypertens 2004, 22(9):1819-1829.

46. Qin XP, Zeng SY, Li D, Chen QQ, Luo D, Zhang Z, Hu GY, Deng HW, Li YJ: Calcitonin gene-related peptide-mediated depressor effect and inhibiting vascular hypertrophy of rutaecarpine in renovascular hypertensive rats. J Cardiovasc Pharmacol 2007, 50(6):654-659.

47. Li D, Peng J, Xin HY, Luo D, Zhang YS, Zhou Z, Jiang DJ, Deng HW, Li YJ: Calcitonin gene-related peptide-mediated antihypertensive and antiplatelet effects by rutaecarpine in spontaneously hypertensive rats. Peptides 2008, 29(10):1781-1788.

48. Qin XP, Zeng SY, Tian HH, Deng SX, Ren JF, Zheng YB, Li D, Li YJ, Liao DF, Chen SY: Involvement of prolylcarboxypeptidase in the effect of rutaecarpine on the regression of mesenteric artery hypertrophy in renovascular hypertensive rats. Clin Exp Pharmacol Physiol 2009, 36(3):319-324.

49. Sheu JR, Hung WC, Lee YM, Yen MH: Mechanism of inhibition of platelet aggregation by rutaecarpine, an alkaloid isolated from Evodia rutaecarpa. Eur J Pharmacol 1996, 318(2-3):469-475.

50. Sheu JR, Kan TC, Hung WC, Su CH, Lin CH, Lee YM, Yen MH: The antiplatelet activity of rutaecarpine, an alkaloid isolated from Evodia rutaecarpa, is mediated through inhibition of phospholipase C. Thromb Res 1998, 92(2):53-64.

51. Sheu JR, Hung WC, Wu CH, Lee YM, Yen MH: Antithrombotic effect of rutaecarpine, an alkaloid isolated from Evodia rutaecarpa, on platelet plug formation in vivo experiments. Br J Pharmacol 2000, 110(1):110-115.

52. Zhou Z, Peng J, Wang CJ, Li D, Li TT, Hu CP, Chen XP, Li YL: Accelerated senescence of endothelial progenitor cells in hypertension is related to the reduction of calcitonin gene-related peptide. J Hypertens 2010, 28(5):931-939

53. Ding JS, Gao R, Li D, Peng J, Ran LL, Li YL: Solid dispersion of rutaecarpine improved its antihypertensive effect in spontaneously hypertensive rats. Biopharm Drug Dispos 2008, 29(9):495-500.

54. Chen Z, Hu G, Li D, Chen J, Li Y, Zhou H, Xie Y: Synthesis and vasodilator effects of rutaecarpine analogues which might be involved transient receptor potential vanilloid subfamily, member I (TRPVI). Bioorg Med Chem 2009, 17(6):2351-2359.

55. Selkoe DJ, Podlisny MB: Deciphering the genetic basis of Alzheimer's disease. Ann Rev Genomics Hum Genet 2002, 3:67-99.

56. Perry EK: The cholinergic hypothesis-ten years on. Br Med Bull 1986, 42:63-69.

57. Cumming JL, Vinters HV, Cole GM, Khachaturian ZS: Alzeheimer's disease: Etiologies, pathophysiology, cognitive reserve, and treatment opportunities. Neurology 1998, 51(Suppl 1):S2-S17.

58. Parihar MS, Hemnani T: Alzheimer's disease pathogenesis and therapeutic interventions. J Clin Neurosci 2004, 11(5):456-467.

59. Haji A, Momose Y, Takeda R, Nakanishi S, Hiriachi T, Arisawa M: Increased feline cerebral blood flow induced by dehydroevodiamine hydrochloride from Evodia rutaecarpa. J Nat Prod 1994, 57(3):387-389.
60. Park CH, Kim SH, Choi W, Lee YJ, Kim JS, Kang SS, Suh YH: Novel anticholinesterase and antiamnesic activities of dehydroevodiamine, a constituent of Evodia rutaecarpa. Planta Med 1996, 62(5):405-409.

61. Park CH, Lee YJ, Lee SH, Choi SH, Kim HS, Jeong SJ, Kim SS, Suh YH: Dehydroevodiamine. $\mathrm{HCl}$ prevents impairment of learning and memory and neuronal loss in rat models of cognitive disturbance. $J$ Neurochem 2000, 74(1):244-253.

62. Wang HH, Chou CJ, Liao JF, Chen CF: Dehydroevodiamine attenuates beta-amyloid peptide-induced amnesia in mice. Eur J Pharmacol 2001, 413(2-3):221-225

63. Peng JH, Zhang CE, Wei W, Hong XP, Pang XP, Wang JZ: Dehydroevodiamine attenuates tau hyerphosphorylation and spatial memory deficit induced by activation of glycogen synthase kinase-3 in rats. Neuropharmacology 2007, 52(7):1521-1527.

64. Park CH, Choi SH, Kim CH, Seo JH, Koo JW, Rah JC, Kim HS, Jeong SJ, Joo WS, Lee YL, Kim YS, Kim MS, Suh YH: General pharmacology of indole [2', 3':3,4] pyridol[2,1-b]quinazolinium-5,7,8,13-tetrahydro-14-methyl-5-oxo-chloride, a new anti-dementia agent. Arzneimittelforschung 2003, 53(6):393-401.

65. Decker M: Novel inhibitors of acetyl- and butyrylcholinesterase derived from the alkaloids dehydroevodiamine and rutaecarpine. Eur J Med Chem 2005, 40(3):305-313.

66. Park EJ, Suh YH, Kim JY, Choi S, Lee CJ: Long-lasting facilitation by dehydroevodiamine $\mathrm{HCl}$ of synaptic responses evoked in the CA1 region of rat hippocampal slices. Neuroreport 2003, 14(3):399-403.

67. Lim DK, Lee YB, Kim HS: Effects of dehydroevodiamine exposure on glutamate release and uptake in the cultured cerebellar cells. Neurochem Res 2004, 29(2):407-411.

68. Fang J, Liu R, Tian Q, Hong XP, Wang SH, Cao FY, Pan XP, Wang JZ: Dehydroevodiamine attenuates calyculin A-induced tau hyperphosphorylation in rat brain slices. Acta Pharmacol Sin 2007, 28(11):1717-1723.

69. Kim ST, Kim JD, Lyu YS, Lee MY, Kang HW: Neuroprotective effect of some plant extracts in cultured CT105-induced PC12 cells. Biol Pharm Bull 2006, 29(10):2021-2024.

70. Kano Y, Zong QN, Komatsu K: Pharmacological properties of galenical preparation, XIV. Body temperature retaining effect of the Chinese traditional medicine, 'goshuyu-to' and component crude drugs. Chem Pharm Bull (Tokyo) 1991, 39(3):690-692.

71. Tsai TH, Lee TF, Chen CF, Wang LC: Thermoregulatory effects of alkaloids isolated from Wu-Chu-Yu in afebrile and febrile rats. Pharmacol Biochem Behav 1995, 50(2):293-298.

72. Kobayashi Y, Nakano Y, Kizaki M, Hoshikuma K, Yokoo Y, Kamiya T: Capsaicin-like anti-obese activities of evodiamine from fruits of Evodia rutaecarpa, a vanilloid receptor agonist. Planta Med 2001, 67(7):628-633.

73. Wang T, Wang Y, Kontani Y, Kobayashi Y, Sato Y, Mori N, Yamashita H: Evodiamine improves diet-induced obesity in a uncoupling proteun-1independent manner: Involvement of antiadipogenic mechanism and extracellularly regulated kinase/mitogen-activated protein kinase signaling. Endocrinology 2008, 149(1):358-366.

74. Wang T, Wang Y, Yamashita H: Evodiamine inhibits adipogenesis via the EGFR-PKC alpha-ERK signaling pathway. FEBS 2009, 583(22):3655-3659.

75. Hu Y, Fahmy H, Zjawiony JK, Davies GE: Inhibitory effect and transcriptional impact of berberine and evodiamine on human white preadipocyte differentiation. Fitoterapia 2010, 81(4):259-268.

76. Bak EJ, Park HG, Kim JM, Kin JM, Yoo YJ, Cha JH: Inhibitory effect of evodiamine alone and in combination with rosiglitazone on in vitro adipocyte differentiation and in vivo obesity related to diabetes. Int $J$ Obes (Lond) 2010, 34(2):250-260.

77. Willie JT, Chemelli RM, Sinton CM, Yanagisawa W: To eat or to sleep? Orexin in the regulation of feeding and wakefulness. Neuroscience 2001, 24:429-458.

78. Shimada M, Tritos NA, Lowell BB, Flier JS, Maratos-Flie E: Mice lacking melanin-concentrating hormone are hypophagic and lean. Nature 1998, 396:670-674

79. Wolfrum C, Besser D, Luca E, Stoffel M: Insulin regulates the activity of forkhead transcription factor Hnf-3beta/Foxa-2 by Akt-mediated phosphorylation and nuclear/cytosolic localization. Proc Natl Acad Sci USA 2003, 100:11624-11629.

80. Silva JP, Von Meyenn F, Howell J, Thorens B, Wolfrum C: Regulation of adaptive behaviour during fasting by hypothalamic Foxa2. Nature 2009, 462:646-651. 
81. Shi J, Yan J, Lei Q, Zhao J, Chen K, Yang D, Zhaox X, Zhang Y: Intragastric administration of evodiamine suppresses NPY and AgRP gene expression in the hypothalamus and decreases food intake in rats. Brain Res 2009, 1247:71-78.

82. Kim SJ, Lee SJ, Lee S, Chae S, Han MD, Mar W, Nam KW: Rutaecarpine ameliorates body weight gain through the inhibition of orexigenic neuropeptides NPY and AgRP in mice. Biochem Biophys Res Commun 2009, 389(3):437-442.

83. Suzen S, Buyukbingol E: Recent studies of aldose reductase enzyme inhibition for diabetic complications. Curr Med Chem 2003, 10(15):1329-1352.

84. Kato A, Yasuko H, Goto H, Hollinshead J, Nash RJ, Adachi I: Inhibitory effect of rhetsinine isolated from Evodia rutaecarpa on aldose reductase activity. Phytomedicine 2009, 16(2-3):258-261.

85. Yu LL, Liao JF, Chen CF: Anti-diarrheal effect of water extract of Evodia Fructus in mice. J Ethnopharmacol 2000, 73(1-2):39-45.

86. Yu X, Wu DZ: Protective effects of Evodia rutaecarpa, water extract on ethanol-induced rat gastric lesions. Zhongguo Zhong Yao Za Zhi 2006, 31(21):1801-1803.

87. Yu X, Wu DZ, Yuam JY, Zhang RR, Hu ZB: Gastroprotective effect of fructus evodiae water extract on ethanol-induced gastric lesions in rats. Am J Chin Med 2006, 34(6):1027-1035.

88. Wu CL, Hung CR, Chang FY, Lin LC, Pau KY, Wang PS: Effects of evodiamine on gastrointestinal motility in male rats. Eur J Pharmacol 2002, 457(2-3):169-176.

89. Zhang T, Wang MW, Chen SW: Anti-emetic effect of ethanol extract from 'Wuzhuyu broth'. Zhougguo Zhong Yao Za Zhi 2002, 27(11):862-866.

90. Kim BJ, Kim JH, Kim HP, Heo MY: Biological screening of 100 plant extracts for cosmetic use (II): Anti-oxidative activity and free radical scavenging activity. Int J Cosmet Sci 1997, 19(6):299-307.

91. Shin YW, Bae EA, Cai XF, Lee JJ, Kim DH: In vitro and in vivo antiallergic effects on the fruits of Evodia rutaecarpa and its constituents. Biol Pharm Bull 2007, 30(1):197-199.

92. Ho JN, Lee YH, Lee YD, Jun WJ, Kim HK, Hong BS, Shin DH, Cho HY Inhibitory effect of aucubin isolated from Eucommia ulmoides against UVB-induced matrix metalloproteinase-1 production in human skin fibroblasts. Biosci Biotechnol Biochem 2005, 69(11):2227-2231.

93. Yarosh DB, Galvin JW, Nay SL, Pena AV, Canning MT, Broen DA: Antiinflammatory activity in skin by biomimetic of Evodia rutaecarpa extract from traditional Chinese medicine. J Dermato/ Sci 2006, 42(1):13-21.

94. Beak SM, Paek SH, Jahng Y, Lee YS, Kim JA: Inhibition of UVA irradiationmodulated signaling pathways by rutaecarpine, a quinazolinocarboline alkaloid, in human keratinocytes. Eur J Pharmacol 2004, 49(1-3):19-25.

95. Yamahara J, Yamada T, Kitani T, Naitoh Y, Fujmura H: Antianoxic action and active constituents of Evodia Fructus. Chem Pharm Bull (Tokyo) 1989, 37(7):1820-1822

96. Yamahara J, Yamada T, Kitani T, Naitoh Y, Fujimura H: Antianoxic action of evodiamine, an alkaloid in Evodia rutaecarpa fruit. J Ethnopharmacol 1989, 27(1-2):185-192.

97. Zheng MS, Zhang YZ: Anti-HBsAg herbs employing ELISA technique. Zhongguo Zhong Xi Yi Jie He Za Zhi 1990, 10(9):560-562.

98. Perrett S, Whitfield PJ: Atanine (3-dimethylallyl-4-methoxy-2-quinolone), an alkaloid with anthelmintic activity from the Chinese medicinal plant, Evodia rutaecarpa. Planta Med 1995, 61(3):276-278

99. Rho TC, Bae EA, Kim DH, Oh WK, Kim BY, Ahn JS, Lee HS: Anti-Helicobacter pylori activity of quinolone alkaloids from Evodiae Fructus. Biol Pharm Bull 1999, 22(10):1141-1143.

100. Hamasaki N, Ishii E, Tominaga K, Tezuka Y, Nagaoka T, Kadota S, Kuroki T, Yano l: Highly selective antibacterial activity of novel alkyl quinolone alkaloids from a Chinese herbal medicine, Gosyuyu (Wu-Chu-Yu), against Helicobacter pylori in vitro. Microbiol Immunol 2000, 44(1):9-15.

101. Tominaga K, Higuchi K, Hamasaki N, Hamaguchi M, Takashima T, Tanigawa T, Watanabe T, Fujiwara Y, Tezuke Y, Nagaoka T, Kadota S, Ishii E, Kobayashi K, Arakawa T: In vivo action of novel alkyl methyl quinolone alkaloids against Helicobacter pylori. J Antimicrob Chemother 2002, 50(4):547-552.

102. Tominaga $K$, Higuchi $K$, Hamasaki N, Tanigawa T, Sasaki E, Watanabe T, Fujiwara Y, Oshitani N, Arakawa T, Ishii E, Tezuka Y, Nagaoka T, Kadota S: Antibacterial activity of a Chinese herb medicine, Gosyuyu (Wu-Chu-Yu), against Helicobacter pylori. Nippon Rinsho 2005, 63(Suppl 11):592-599.
103. Tang $Y$, Wu F, Feng $X$, Huang L: Studies on synthesis and bioactivity of 2alkenyl-4(1H)-quinolone. Yaoxue Xuebao 1998, 33(4):269-274.

104. Thuille N, Fille M, Nagl M: Bactericidal activity of herbal extracts. Int J Hyg Environ Health 2003, 206(3):217-221.

105. Khan MR, Kihara M, Omolos AD: Antimicrobial activity of Evodia elleryana. Fitoterapia 2000, 71(1):72-74.

106. Barrows LR, Powan E, Pond CD, Matainaho T: Anti-TB activity of Evodia elleryana bark extract. Fitoterapia 2007, 78(3):250-252.

107. Ratsimamanga-Urverg S, Rasoanivo P, Rakoto-Ratsimamanga A, Le Bras J, Ramiliarisoa O, Savel J, Coulaud JP: Antimalarial activity and cytotoxicity of Evodia fatraina stem bark extracts. J Ethnopharmacol 1991, 33(3):231-236.

doi:10.1186/1749-8546-6-6

Cite this article as: Liao et al:: Anti-inflammatory and anti-infectious effects of Evodia rutaecarpa (Wuzhuyu) and its major bioactive components. Chinese Medicine 2011 6:6.

\section{Submit your next manuscript to BioMed Central and take full advantage of:}

- Convenient online submission

- Thorough peer review

- No space constraints or color figure charges

- Immediate publication on acceptance

- Inclusion in PubMed, CAS, Scopus and Google Scholar

- Research which is freely available for redistribution

Submit your manuscript at www.biomedcentral.com/submit
C) Biomed Central 